\begin{tabular}{|r|l|l|l|l|l|}
\hline Revista Clío América & ISSN: 1909-941X & Vol. 11 & No. 22 & julio - diciembre de 2017 & 219 - 239 \\
\hline \multicolumn{6}{|c|}{ D0I: http://10.21676/23897848.2443 } \\
\hline
\end{tabular}

\title{
El emprendimiento: algunas reflexiones desde un enfoque de revisión
}

The entrepreneurship: some reflections from a review approach

\section{Mario Enrique Uribe Macias \\ Doctor en Gerencia de Proyectos, Magíster en Administración. Profesor Titular de la Universidad del Tolima. Colombia. Email: meuribem@gmail.com \\ ORCID: http://orcid. org/0000-0003-1517-1403}

Tipología: Artículo de revisión Fecha de recibido: abril 26 de 2017

Fecha de aceptación: octubre 23 de 2017

Publicado en línea: noviembre 27 de 2017

Para citar este artículo:

Uribe M., M. (2017). El emprendimiento: algunas reflexiones desde un enfoque de revisión. Clío América, 11(22), 219-239. Doi: $10.21676 / 23897848.2443$
RESUMEN: Usualmente, los elementos relacionados con el emprendimiento se analizan por separado, situación que puede conducir a los interesados a perder la visión holística que lo caracteriza. El objetivo de este artículo es proponer elementos de juicio para ampliar la discusión y posterior realización de estudios empíricos que conduzcan a fortalecer el estado del arte del tema. Para ello, se utilizó la técnica de revisión documental enfocada en seis elementos conceptuales atados al emprendimiento, que van desde lo personal (características del emprendedor, liderazgo, personalidad, capital relacional) hasta lo estructural (emprendimiento corporativo, ecosistema emprendedor). Los resultados se concentran en resaltar las relaciones que se dan entre cada uno de los elementos y el emprendimiento, para evidenciar una fuerte influencia de cada uno de ellos en el quehacer del emprendedor. Se proponen algunas líneas de investigación alrededor de la relación entre el ejercicio del liderazgo y el éxito de los emprendimientos en regiones específicas; así como el efecto del capital relacional en los nuevos emprendimientos individuales y en las empresas.

Palabras clave: liderazgo; personalidad; capital relacional; emprendimiento corporativo; ecosistema emprendedor.

JEL: M10

ABSTRACT: Usually, the elements constituting entrepreneurship are analyzed separately, which can make interested parties to lose the holistic vision characterizing it. This paper aims to propose analytical elements that can help to broaden the discussion and to lay foundations for subsequent empirical studies strengthening the state of the art on the subject. A documental review technique was used, centered around six conceptual elements tied to entrepreneurship --from the personal level (characteristics of the entrepreneur, leadership, personality, relational capital) to the structural one (corporate entrepreneurship, entrepreneurial ecosystem). The results highlight the relationships between the above mentioned elements and entrepreneurship to show the way they influence the work of the entrepreneur as well as the effect of relational capital upon new individual enterprises and companies. Some lines of research are proposed, mainly on the relation between leadership and the success of ventures in specific regions.

Keywords: Leadership; Relational Capital; Corporate Entrepreneurship; Entrepreneurial Ecosystem. 


\section{INTRODUCCIÓN}

El "emprendimiento" puede ser considerado como el conjunto de competencias que se desarrollan en un contexto determinado y que contribuyen a la generación de cosas nuevas. Si bien este concepto se ha atado tradicionalmente a la creación de empresas, no se circunscribe exclusivamente a ello. Siendo así, el emprendimiento incluye un conjunto de variables que se relacionan con lo personal (el emprendedor) y/o lo estructural (el ecosistema emprendedor), y se inserta dentro de las dinámicas empresariales y productivas propias de las economías y de las regiones.

En consecuencia, se ha considerado importante, por un lado, realizar el análisis de tres competencias que se califican como fundamentales en el actuar del emprendedor: el liderazgo, la personalidad y el capital relacional; esto, a partir de las características que desde diferentes ópticas se le reconocen. Por otro lado, se ha buscado complementar el análisis con el tema de emprendimiento corporativo y el de ecosistema emprendedor desde un enfoque estructural, tal como se esquematiza en la Figura 1.

Figura 1.

Esquema general del análisis.

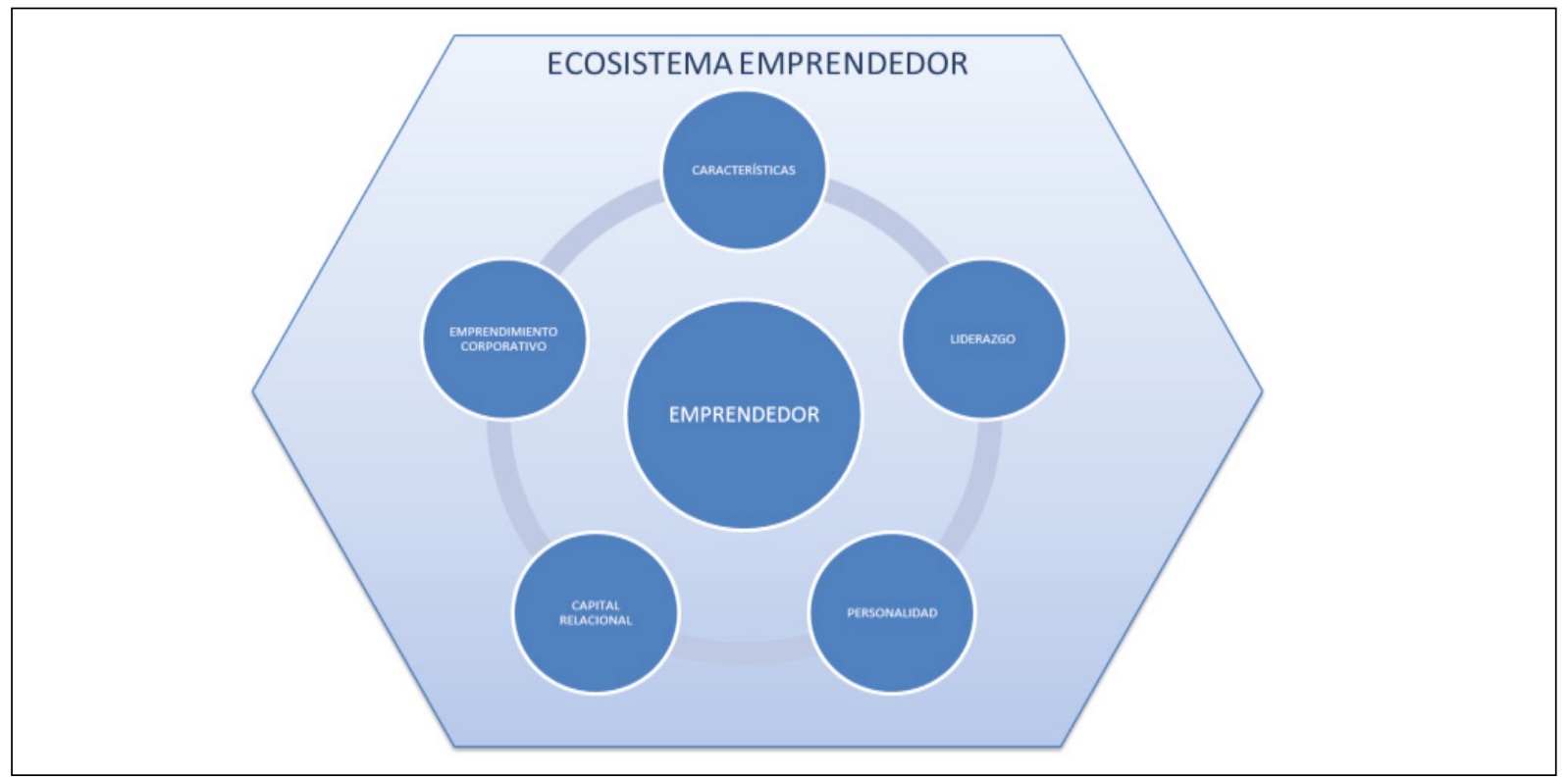

Fuente: elaboración propia.

El objetivo del análisis es proponer elementos de juicio para ampliar la discusión y la posterior realización de estudios empíricos que conduzcan a fortalecer el estado del arte del tema. Para ello, se utilizó la técnica de revisión documental a partir de la consulta de literatura especializada, alrededor de los temas de interés asociados al emprendedor (características, liderazgo, personalidad y capital relacional) y al emprendimiento (emprendimiento corporativo y ecosistema emprendedor).
Esta manera de desarrollar el tema constituye en sí misma una propuesta alrededor del cómo los emprendedores, docentes y estudiantes deben concebir el manejo, la fundamentación y la puesta en práctica del emprendimiento a partir de la incorporación del holismo como una óptica transversal.

Por tal motivo, el artículo se estructura de la siguiente manera: al comienzo, se plantea el tema del emprendimiento como referente básico para 
los demás tópicos: el liderazgo, la personalidad y el capital relacional, todos ellos enfocados en el emprendedor; posteriormente, se abordan los ítems de emprendimiento corporativo y del ecosistema emprendedor $y$, finalmente, se proponen algunas conclusiones y se sugieren líneas de investigación que podrían derivarse del análisis realizado.

\section{El emprendimiento, conceptos generales}

Para enmarcar los conceptos generales relacionados con el emprendimiento, conviene reflejar, en primera instancia, la esencia del término. Al respecto, Rodríguez (2009) plantea que "la palabra emprendimiento se deriva del término francés entrepreneur, que significa estar listo a tomar decisiones 0 a iniciar algo" (p. 96). Por su parte, Cantillón (como se citó en Rodríguez, 2009, p. 97) "introduce por primera vez el concepto moderno de entrepreneur, definido como el individuo que asume riesgos en condiciones de incertidumbre". En este sentido, Rodríguez (2009) plantea dos características: el emprendedor es inteligente y toma riesgos, y toma decisiones con riesgo innovador.

Schumpeter (como se citó en Demirci, 2013) es el primer economista que trató los conceptos de "emprendimiento" e "innovación" juntos. Él definió al emprendedor como una persona que combina los factores existentes en una única y novedosa manera de ofrecer valor. Su definición incluyó nuevos productos, nuevos servicios, nuevos procesos y nuevos mercados. Así también, destaca Demirci (2013) que el emprendimiento es crucial para el desarrollo de los países por su papel fundamental en el crecimiento económico y en la creación y distribución de riqueza.

Para Orrego (2009b), "el emprendimiento se considera una práctica social, susceptible de entenderse según la expresión de la conducta humana" (p. 23). En este sentido, "se orienta el aprendizaje personal y organizacional, en el desarrollo de acciones transformadoras del contexto, en el cual el sujeto potencia sus dimensiones sociales, para emprender y construir tejido social" (Orrego, 2009a, p. 239).

No obstante, afirma Rodríguez (2009) que "el emprendimiento no puede concebirse desde el concepto de oportunidad, ni desde los rasgos del individuo, ni desde sus capacidades para lograr la efectividad. Se concibe desde la integración de las características mencionadas" (p. 106).

La ley 1014 de 2006 del Congreso de la República de Colombia (como se citó en Uribe y Reinoso, 2013) define el emprendimiento como

la capacidad de la persona para crear a partir de significados, aprender a solucionar problemas, con base en sus emociones, su creatividad, sus actitudes y valores personales, lo que le permite adecuarse a un contexto y aprovechar las oportunidades que este brinda para beneficio propio y el de la sociedad en la que está inmerso. Esto le permite fijarse metas y retos para alcanzarlos estableciendo un estilo de vida caracterizado por actitudes, habilidades, valores, competencias, conocimientos en donde están presentes la innovación, la creatividad, la autoconfianza, la ética y la capacidad para analizar el entorno, comprender procesos y desarrollar proyectos (p. 13).

Y complementan el concepto definiendo el emprendimiento

como un conjunto de competencias, que parte de la actitud de la persona, para captar oportunidades de su entorno, lo cual requiere un pensamiento sistémico, convertirlas en ideas innovadoras con base en su creatividad y generar proyectos productivos en diferentes campos, para beneficio propio y de su entorno (Uribe y Reinoso, 2013, p. 14).

Ronstad (como se citó en Varela, 2008) plantea la existencia de competencias emprendedoras como el liderazgo, la responsabilidad, la autonomía, la innovación, la creatividad, la autoconfianza, la toma de decisiones bajo incertidumbre y la habilidad técnica para desarrollar proyectos y tomar la decisión del momento empresarial.

Estos componentes conducen a plantear que las acciones relacionadas con el éxito del emprendimiento dependen de manera importante de una plataforma adecuada para ello, en la que se incluya al gobierno, a la empresa privada, a la academia y al personaje fundamental en el proceso: el emprendedor y su capacidad de conformar redes de cooperación en torno a su proyecto.

En cuanto al emprendedor, Amaru (2008) afirma que este, "en esencia, es una persona que tiene la capacidad de idear y realizar cosas nuevas" (p. 4). Con 
base en esta premisa es conveniente señalar que no todos los integrantes de una organización tienen esa característica, por lo cual debe promoverse al interior de las empresas un entorno propicio que les permita adquirir dichas capacidades.

En esta dirección del análisis, Bolton \& Lane (2012), (como se citó en Wyk y Adonisi, 2012), destacan que los continuos cambios en el ambiente económico obligan a los negocios a nutrirse del ambiente emprendedor para asegurar la competitividad global, el crecimiento y la supervivencia. Exponen que hay una continua necesidad por investigar qué factores contribuyen al desarrollo y crecimiento de las empresas emprendedoras.

El planteamiento anterior se ve complementado al hacer presente la importancia que los creadores de empresa deben conceder al medio en el cual se desarrollan. Un concepto relativo a esta premisa es el que denominan "ecosistema de emprendimiento", que corresponde al escenario donde se cuenta con la participación de estamentos públicos y privados, de la academia y de los emprendedores. Esta red debe garantizar la infraestructura y los recursos necesarios para el desarrollo de las actividades de emprendimiento. Por tal motivo, al final del artículo se exponen de manera más profunda los conceptos de "emprendimiento corporativo" y "ecosistema emprendedor", de tal forma que se pueda tener una visión holística del proceso asociado al emprendimiento.

\section{Las características del emprendedor}

La importancia de un conjunto de características que son inherentes al emprendimiento se puede desvelar en la afirmación realizada por Minniti y Bygrave (1999): “Distintos individuos pueden estar en frente de una oportunidad rentable. Algunos la verán y otros no. De aquellos que la ven, algunos la seguirán y otros no. Los individuos que aprovechan la oportunidad se vuelven empresarios y los demás no" (p. 42).

En general, cuando se analizan las características del emprendedor, se reconoce la existencia de al menos los siguientes factores: personales, de vocación emprendedora, potenciadores, generadores, y determinantes (Figura 2). Cada uno de ellos juega un rol específico en la actuación del emprendedor, como se señala a continuación.

Figura 2.

Categorias de factores asociados al emprendedor.

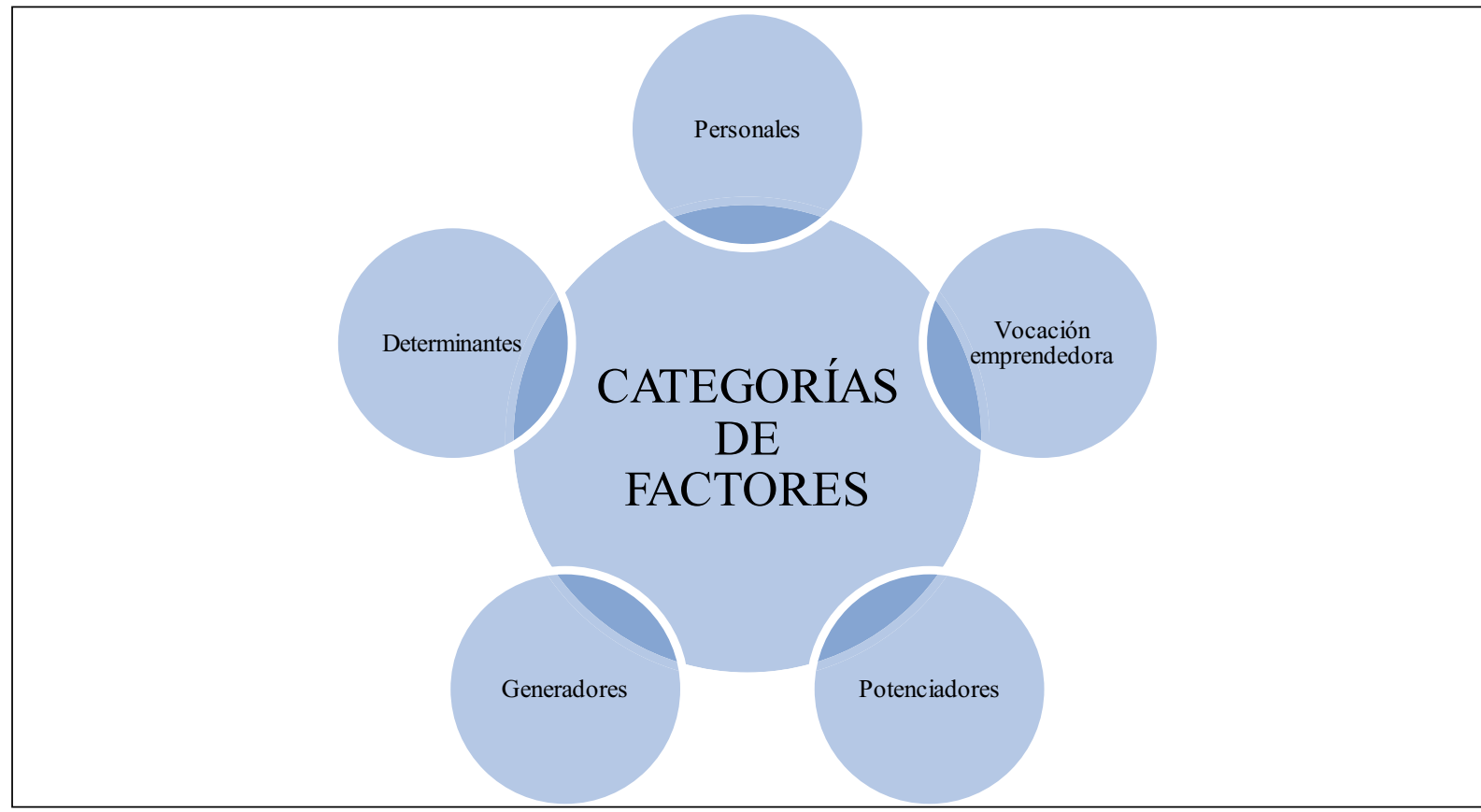

Fuente: elaboración propia. 
En primer lugar, los factores personales pertenecen al individuo: son propios de la manera en que se relaciona con su entorno e influencian la forma en que realiza las tareas que acomete. A esta categoría pertenecen "la creatividad e iniciativa, la auto-confianza, la energía y capacidad de trabajo, la perseverancia y [el] liderazgo, la aceptación del riesgo, la necesidad de logro, [...] la tolerancia al cambio y el manejo de los problemas" (Vargas y Campos, 2011, p. 14).

En segundo lugar, los factores de vocación emprendedora conducen al individuo a adelantar las acciones requeridas para llevar a buen término sus emprendimientos. Se reconocen los siguientes: motivación personal, espíritu emprendedor, oportunidad de negocios, tradición familiar y autoempleo (Santamaría, Moreno, Torres y Cadrazco, 2013; Pérez, Espinoza, Tapia, Márquez y Acevedo, 2006).

En tercer lugar, entre los factores potenciadores se encuentran: la ambición, el espíritu de sacrificio, la asunción de riesgos, la insatisfacción laboral, la audacia, el entusiasmo, y la ilusión. Todos estos factores actúan sobre los anteriores para conducir la energía humana hacia la toma de decisiones para emprender; esto, en palabras de García, Álvarez y Reyna (2007), se interpreta como el conjunto de características que contribuyen a desarrollar el espíritu emprendedor.

En cuarto lugar, los factores generadores contienen las características esenciales del espíritu emprendedor (García et al., 2007) y sientan las bases sobre las cuales se construye el nuevo emprendimiento: creatividad, fuerza de voluntad, vanidad, profesionalidad, confianza, selección efectiva de personal, buen carácter e independencia.

Finalmente, los factores determinantes conllevan a la decisión de hacer algo nuevo; en este sentido, despejan la incertidumbre que pudiera existir en el emprendedor. En esta categoría se encuentran: "creatividad e innovación, tenacidad, auto-confianza, liderazgo y coordinación, comunicación, negociación, responsabilidad, altruismo, capacidad para asumir riesgos, y honestidad" (Borjas, 2003, p. 135).
Cuando se analizan estas características se encuentra que, para el desarrollo del emprendimiento en cabeza del emprendedor, existen tres elementos fundamentales: lo cognitivo, lo afectivo, y lo conductual. Es decir que no solo se requiere contar con el conocimiento para tener éxito al emprender sino que se deben tener también los deseos de hacerlo: así, las metas se sienten como propias y resultan agradables para la persona. Pero, además de esto, se hace necesario el hacer, pues es gracias a este que resulta posible convertir los sueños en realidad.

A su vez, el modelo $\mathrm{GEM}^{1}$ plantea tres condiciones: la capacidad de percibir las oportunidades, las habilidades para poder aprovecharlas y los conocimientos para potenciarlas y hacerlas sostenibles.

Por otra parte, en términos empíricos, en un estudio realizado por Cujiño y Uribe (2014) sobre las decisiones estratégicas tomadas a lo largo de su historia empresarial por dos emprendedores tolimenses, se encuentran como características comunes de ellos las siguientes: innovación, auto-confianza, liderazgo, negociación, capacidad para asumir riesgos, capacidad de trabajo, liderazgo, perseverancia, y oportunidad de negocio.

En el mismo sentido, Acuña, Araque, Rubio y Uribe (2015) adelantaron una investigación conducente a explicar las causas del cierre de empresas de emprendedores pioneros tolimenses, de cuyos resultados se puede concluir que las características comunes encontradas en dichos empresarios son: solidaridad, ética, ayuda mutua, selección efectiva de personal, innovación, necesidad de acumular capital, capacidad de riesgo, liderazgo empresarial, creatividad y conocimiento.

\section{El liderazgo y el emprendimiento, actuaciones relacionadas}

Helland y Winston, (como se citó en Zárate y Matviuk, 2012), expresan que

el liderazgo se ha estudiado desde dos puntos de vista; el primero ve al liderazgo como un cargo de jerarquía en las organizaciones y el otro, ve al

1 Global Entrepreneurship Monitor. 
liderazgo como un proceso de influencia social que sucede en un sistema social (p. 91).

Por su parte, Hotgetts y Altman, (como se citó en Gómez, 2008), plantean

que el liderazgo forma parte del trabajo de un administrador [...y que como tal] es el proceso de influir en las personas para encauzar sus esfuerzos hacia la consecución de una meta o metas específicas. Esta influencia, de acuerdo con estos autores, está determinada por dos factores: 1) la posición de poder del líder, que es la autoridad formal que acompaña a un puesto específico, y 2) la disposición que tiene el subordinado a obedecer (p. 162).

En el mismo sentido, Mintzberg (1980) afirma que el papel más importante del líder es influir en otros para lograr con entusiasmo los objetivos planteados. A su vez, el Centro de Empresas y Negocios Santiago Innova (2015) plantea como una de las competencias emprendedoras y empresariales el liderazgo, el cual es definido por la Conferencia de Consejos Sociales (2015) como la

habilidad necesaria para orientar la acción de los grupos humanos en una dirección determinada, inspirando valores de acción y anticipando escenarios de desarrollo de la acción de ese grupo, además de la habilidad para fijar objetivos, realizar el seguimiento de dichos objetivos y la ejecución de la capacidad de dar feedback integrando las opiniones de los otros (p. 2).

El libro Lecciones de Winston Churchill CEO, escrito por Alan Axelrod (como se citó en Maestres, 2009), intenta construir un marco teórico-práctico que aporte analogías para el pensamiento de los líderes actuales; el autor del artículo destaca del libro los siguientes principios: "asimilar las lecciones", basado en la capacidad de aprendizaje del individuo; "lo más importante que debe administrar un líder es su ego", para evitar la arrogancia propia que ciega; "la importancia de ejercer la justicia", para evitar caer en la tiranía, y "convertir las dificultades en oportunidades de éxito", en desarrollo de su pensamiento estratégico para la generación de nuevas visiones.
En palabras de Mann (como se citó en Gómez, 2008), las características generales del liderazgo se clasifican en tres categorías: habilidades técnicas, habilidades interpersonales y habilidades conceptuales; estas, hacen que el líder pueda desplegar toda su capacidad para

decidir lo que debe hacerse y luego lograr que los demás quieran hacerlo. Liderazgo es el proceso de influir en las actividades de un individuo 0 individuos, en las decisiones que se tomen y los esfuerzos que se realicen encaminados a metas, en una situación determinada (Gómez, 2008, p. 163).

Por último, Adair (1990) establece que algunas de las funciones del liderazgo son: 1) establecer los objetivos, 2) planear, 3) instruir, 4) controlar, y 5) retroalimentar.

Ahora bien, para determinar la existencia de semejanzas entre las competencias propias del emprendimiento y las del liderazgo es necesario reconocer la gran cantidad de conceptos y definiciones con respecto al término "competencia", motivo por el cual es conducente apoyarse en Ferrández \& Sánchez (2014) que establecen los rasgos comunes de sus diversas definiciones, a saber:

1) son características 0 atributos personales: conocimientos, habilidades, aptitudes, rasgos de carácter, conceptos de uno mismo; 2) están relacionados con ejecuciones que producen resultados exitosos, se manifiestan por tanto en la ejecución; 3) logran resultados en diferentes contextos y, por ello, no son características estables; 4) son transferibles, en el sentido de que el sujeto las puede aplicar a cualquier actividad, sector o función; 5) son susceptibles de ser entrenadas y desarrolladas a partir de programas de formación (p. 2).

Tras el análisis de los diferentes elementos conceptuales presentados en el ítem anterior, se puede afirmar, en primera instancia, que existe una clara relación entre el emprendimiento y el liderazgo: mientras que en el emprendimiento se incorporan la toma de decisiones, la iniciativa y la orientación hacia la generación de transformaciones y la auto- 
confianza, entre otras, en el ejercicio del liderazgo estos elementos se incorporan para influir sobre otros, por lo que se requiere la proacción, la decisión oportuna, la intención de transformar, la seguridad en sí mismo, y demás.

En este mismo sentido, los dos conceptos (y las prácticas que de ellos se derivan) son autosostenibles e independientes; es decir, cada cual se puede desarrollar autónomamente. Sin embargo, parece existir una concepción según la cual el liderazgo está incluido en el emprendimiento. Así, se considera al liderazgo como una de las competencias del emprendimiento en cuanto este es visto como un atributo personal del emprendedor que se relaciona con la producción de resultados exitosos en la ejecución de sus emprendimientos, en cualquier contexto y sector, y que se puede desarrollar mediante formación.

En la Tabla 1 se presentan, en paralelo, algunas de las competencias relacionadas con el emprendimiento y con el liderazgo, producto de la interpretación de los autores citados en el ítem anterior. Es posible deducir que existen semejanzas entre las competencias señaladas por ambos, siendo muy tenues, en ocasiones, las líneas que los separan y los unen, por lo que tienden a confundirse. Para ilustrar la afirmación anterior, valdría preguntarse, por ejemplo: ¿es que acaso el pensamiento estratégico no es en sí mismo pensamiento sistémico?, 0, ¿no se requiere, para pensar estratégicamente, tener una visión sistémica, propia y derivada de una manera de pensar ídem?

\section{Tabla 1.}

Competencias del emprendimiento y del liderazgo

\begin{tabular}{|l|l|}
\hline \multicolumn{1}{|c|}{ EMPRENDIMIENTO } & \multicolumn{1}{|c|}{ LIDERAZGO } \\
\hline Toma de decisiones para emprender & Toma de decisiones para influir sobre otros \\
\hline Iniciativa & Proactividad \\
\hline Orientación hacia la transformación & Intención de transformar, con otros \\
\hline Autoconfianza & Seguridad en sí mismo \\
\hline Pensamiento sistémico & Pensamiento estratégico \\
\hline Creatividad & Asimilación de las lecciones \\
\hline Orientación a las metas & Orientación a los objetivos \\
\hline
\end{tabular}

Fuente: elaboración propia.

En síntesis, el liderazgo es un proceso que permite influir en las personas mediante la utilización de habilidades técnicas, interpersonales y conceptuales, con el fin de encauzar sus esfuerzos hacia la consecución de una meta o metas específicas. El emprendimiento y el liderazgo presentan características comunes, entre las que se encuentran la toma de decisiones, la orientación hacia objetivos y metas, el pensamiento sistémico y estratégico, y demás, que conducen a afirmar que existe similitud entre sus competencias. Así, es posible concluir que los dos conceptos están estrechamente ligados entre sí en sus características, en su funcionamiento y en sus resultados, por lo que requieren de emprendedores líderes para su ejercicio. 


\section{La personalidad y su influencia en el emprendimiento}

Otro de los aspectos que influencian el emprendimiento es la personalidad. Con relación a ella, Blanco (2007) afirma que "La personalidad se refiere al conjunto de características relativamente estables que regulan la forma como los seres humanos se relacionan con su entorno. En consecuencia, la personalidad de un individuo puede afectar su desempeño en las tareas que emprende" (p. 44).

Melucci (como se citó en Andrés, Castañeiras y Richaud, 2014) afirma que la personalidad "implica los modos esencialmente estables y consistentes en los cuales los individuos piensan, sienten y actúan en una variedad de situaciones" (p. 219); mientras que, por su parte, Hermán (como se citó en Andrés et al., 2014) plantea que esta "no se equipara con el comportamiento concreto en una situación, sino que hace referencia a un patrón de conducta propio de cada ser humano, relativamente permanente y estable" (p. 219).

Las características de la personalidad del individuo influyen en su comportamiento $y$, por ende, en su desempeño dentro de una organización. Dicha influencia depende, según Blanco (2007), de qué tan consciente es el individuo de sus características, así como de su capacidad para controlarlas. Mientras que para Rodríguez y Díaz (1997), en contraste, hay cinco factores (rasgos) que marcan la personalidad de cualquier individuo; algunas de las escalas que los reflejan son presentadas en la Tabla 2.

\section{Tabla 2.}

Factores de la personalidad con sus escalas.

\begin{tabular}{|c|c|c|}
\hline No. & FACTOR & ESCALAS \\
\hline 1 & Extraversión-introversión & $\begin{array}{l}\text { Callado-comunicativo } \\
\text { Reservado-expresivo } \\
\text { Introvertido-extrovertido } \\
\text { Desenvuelto-tímido } \\
\text { Inhibido-desinhibido }\end{array}$ \\
\hline 2 & Agradable-desagradable & $\begin{array}{l}\text { Bondadoso-no bondadoso } \\
\text { Agradable-desagradable } \\
\text { Cooperativo-no cooperativo } \\
\text { Considerado-no considerado } \\
\text { Cortés-descortés }\end{array}$ \\
\hline 3 & Concienzudo-reflexivo & $\begin{array}{l}\text { Cuidadoso-descuidado } \\
\text { Cumplido-incumplido } \\
\text { Estudioso-perezoso } \\
\text { Responsable-irresponsable } \\
\text { Organizado-desorganizado }\end{array}$ \\
\hline 4 & Estabilidad emocional (calmado-ansioso) & $\begin{array}{l}\text { Tranquilo-nervioso } \\
\text { Pacífico-agresivo } \\
\text { Calmado-temperamental } \\
\text { Sereno-ansioso } \\
\text { Estable-inestable } \\
\text { No envidioso-envidioso }\end{array}$ \\
\hline
\end{tabular}




\begin{tabular}{|c|c|c|}
\hline No. & FACTOR & ESCALAS \\
\hline 5 & Abierto-cerrado (intelectual y sensitivamente) & $\begin{array}{l}\text { Imaginativo-no imaginativo } \\
\text { Creativo-no creativo } \\
\text { Intelectual-no intelectual } \\
\text { Culto-inculto } \\
\text { Accesible-inaccesible } \\
\text { Conocedor-ignorante } \\
\text { Analítico-no analítico }\end{array}$ \\
\hline
\end{tabular}

Fuente: elaboración propia, basada en Rodríguez y Díaz (1997).

Al respecto, plantea McCrae (citado por Contreras, Espinosa y Esguerra, 2009) que varios estudios han indicado que este modelo refleja una estructura universal de la personalidad y es sensible a las diferencias culturales.

En cuanto a la relación con el emprendimiento, se advierte que no hay emprendimiento sin emprendedor, ya que este (el emprendimiento) se entiende como una capacidad o un conjunto de competencias, de habilidades, de rasgos, que se dan en un individuo y que lo impulsan a actuar de una manera proactiva, sistémica, creativa, autónoma y en el ejercicio de un verdadero liderazgo.

Siendo así, los aspectos inherentes a la persona humana cobran gran importancia, se vuelven protagónicos, vitales, para el comportamiento emprendedor. Es así como aparece el concepto de la "personalidad", entendida como una sumatoria de características que se agrupan y comportan de tal forma que hacen que el individuo se relacione con su entorno de una manera claramente determinada.

Es decir, en el factor extraversión-introversión el emprendedor debe ser comunicativo, expresivo y desenvuelto; en el factor agradable-desagradable, debe ser agradable, cooperativo y cortés; en el concienzudo-reflexivo, debe actuar cuidadosamente, ser cumplido, estudioso, responsable y organizado; en el calmado-ansioso debe ser tranquilo, sereno y estable $y$, finalmente, en el factor abierto-cerrado debe ser imaginativo, creativo, accesible, conocedor y analítico. En la medida en que la persona desarrolle estos rasgos de la personalidad será más emprendedor, mientras que en cuanto se aleje de este perfil ideal, su nivel de emprendimiento se empobrecerá. Como compendio de este ítem, es importante recordar que la personalidad es un conjunto de características que se comportan de manera generalmente estable y que impactan la relación del individuo con su entorno. Dichas características (conocidas como "escalas") se pueden agrupar en cinco factores, a saber: extraversión-introversión, agradable-desagradable, concienzudo-reflexivo, calmado-ansioso, y abierto-cerrado. El emprendedor, en esa gama de características, deberá ejercitar las de ser comunicativo, expresivo, desenvuelto, agradable, cooperativo, cortés, cuidadoso, cumplido, estudioso, responsable, organizado, tranquilo, sereno, estable, imaginativo, creativo, accesible, conocedor y analítico. El esquema de estas escalas, así como los factores aplicables al emprendimiento, se pueden observar en la Figura 3. 


\section{Figura 3.}

Factores y escalas aplicables en el emprendimiento.

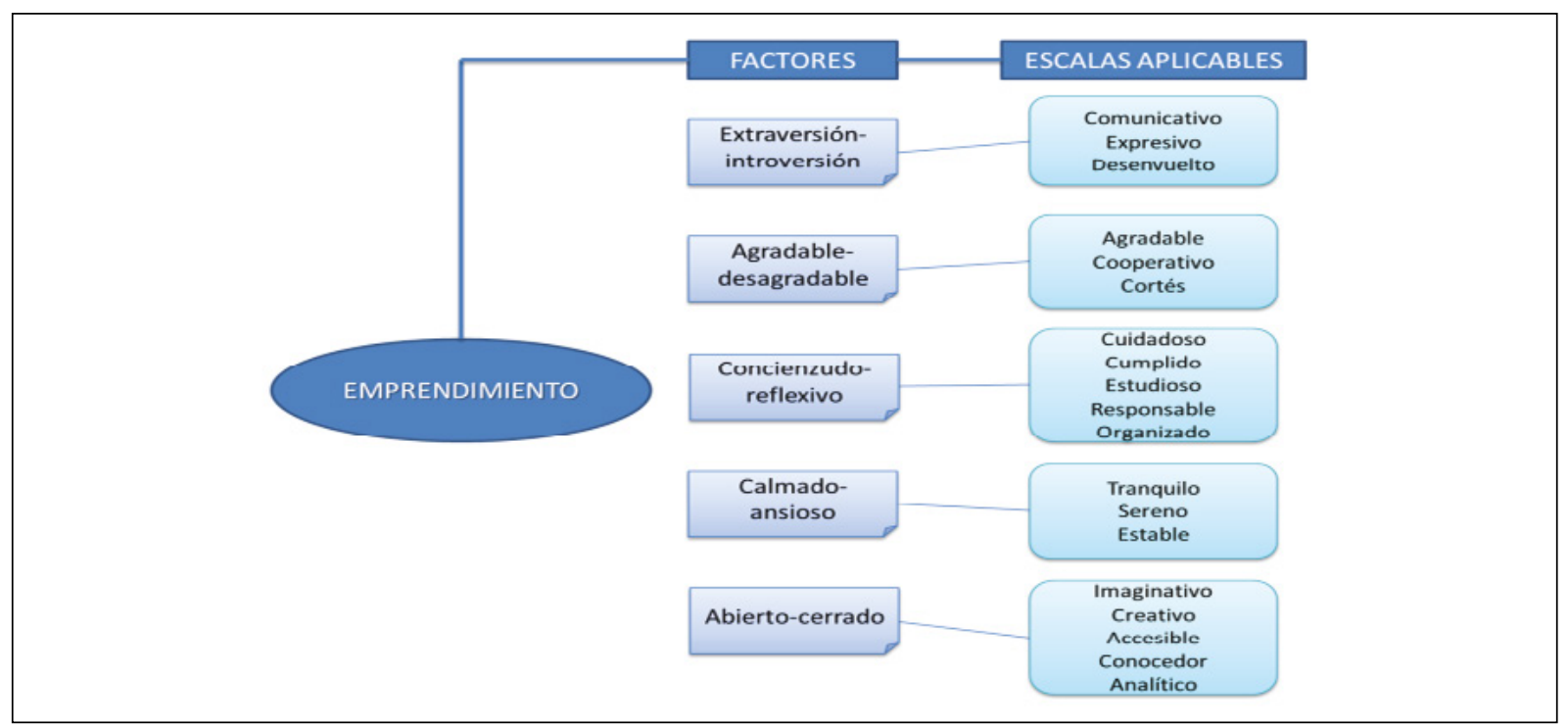

Fuente: elaboración propia basada en Rodríguez y Díaz (1997).

\section{El capital relacional y su importancia para el emprendimiento}

Abdul (2010) afirma que

el capital relacional se refiere a las relaciones entre personas. Es la riqueza que cada persona posee en sus amigos, familiares, conocidos, equipos de trabajo, compañeros de estudio, colegas y todas las demás personas con las cuales se puede relacionar y con quienes podría realizar negociaciones, transacciones y otros movimientos orientados al bienestar y la generación de riqueza económica. Todos los seres humanos podemos construir redes relacionales, las cuales se convierten a través del tiempo en activos de generación de riqueza. El Capital Relacional de una persona equivale a la red de allegados y contactos que realiza y sostiene a través del tiempo. (p. 18)

En cuanto a este concepto, González y Rodenes (2008) refieren que, por su parte, el Modelo Intellectus $^{2}$ define a este tipo de capital como el conjunto de conocimientos que se incorporan a la

2 De la Universidad Autónoma de Madrid organización y a las personas como consecuencia del valor derivado de las relaciones que mantienen con los agentes del mercado y con la sociedad en general.

En este mismo sentido, Delgado, Martín, Navas y Cruz (2011) plantean que

el capital relacional puede definirse como el conjunto de conocimientos que se generan debido a las relaciones institucionales que mantiene una empresa con otros agentes (clientes, proveedores, aliados) y que le reporta un valor y una base de conocimientos necesarios para realizar su actividad de una manera más eficiente. (p. 209)

Al respecto, Capello y Faggian (2005) establecen que estas relaciones que se "derivan de un fuerte sentido de pertenencia y una alta capacidad desarrollada de cooperación, típica de personas e instituciones culturalmente similares pueden ser: relaciones de mercado, relaciones de poder y la cooperación establecida entre empresas, instituciones y personas" (p. 77).

Ahora bien, en lo referente a los componentes del capital relacional, Castellanos y Castellanos (2010) 
plantean que son dos: el capital de negocios y el capital social. El primero es el valor que representa para la organización las relaciones que mantiene con los principales [...Stakeholders, definidos por Argandoña (2010) como cualquier grupo o individuo que puede afectar o ser afectado por la consecución de los objetivos de la empresa,] vinculados con su proceso de negocio básico: clientes, proveedores, accionistas, inversionistas, aliados, competidores e instituciones de promoción y mejora de la calidad, principalmente (p. 4).

El segundo, el capital social, se refiere al "valor que representa para la organización las relaciones que mantiene con los agentes sociales que actúan en su entorno, expresado en términos de nivel de integración, compromiso, cooperación, conexión y responsabilidad social" (Castellanos y Castellanos, 2010, p. 4), los cuales pueden ser: administraciones públicas, medios de comunicación e imagen corporativa, organizaciones para la defensa del medio ambiente, organizaciones sociales y reputación corporativa.

Como información empírica al respecto, la investigación de Delgado et al. (2011), en las empresas manufactureras del sector de tecnología en España, reportó que es el capital relacional el componente que más explica los factores de innovación del producto e innovación del proceso mediante la adquisición de información y conocimiento por la relación de las empresas con otros agentes. Igualmente, Seguí y Server (2010), en un estudio realizado a las cooperativas de crédito españolas, encontraron que el capital relacional provee la información necesaria para la toma de decisiones, teniendo como base el valor generado por los grupos de referencia tanto internos como externos, y permitiendo así una mayor satisfacción a los clientes.

Con el fin de articular el tema del capital relacional con el de emprendimiento, es importante tratar el concepto de "espíritu empresarial", sobre el cual Jiménez, Lozano y Varela (1995) afirman que:

El hombre, desde sus primeros pasos en la tierra, ha sido el artífice fundamental de todas las innovaciones y modificaciones que hoy percibimos en nuestro medio ambiente, buscando siempre mejores condiciones de vida, un mayor desarrollo personal y comunitario, una mayor sensación de felicidad, un nivel de vida más acorde con sus expectativas, 0 sea buscando lo que la cultura humana ha asociado al vocablo PROGRESO (p. 13).

Si bien se hace una generalización a toda la especie humana, queda claro en estas afirmaciones que las cualidades que debe reunir todo emprendedor no son generalizables. No obstante, el progreso y los avances tecnológicos existentes se deben precisamente a aquellos individuos que rompieron paradigmas, abandonaron su zona de bienestar, se arriesgaron $y$, en no pocas oportunidades, fracasaron.

A su vez, Chiavenato y Sapiro (2011) elevan al emprendedor a una condición de creador de organizaciones y de estratega, al asignarle la capacidad de descubrir nuevas oportunidades fortuitas con rapidez antes de que las descubran otros aventureros. En este contexto exponen que el término emprendedor, del francés entrepreneur, designa a una persona que no se conforma con el statu quo, que toma iniciativas, asume riesgos y comienza algo nuevo. En realidad, el emprendedor es la persona que consigue que las cosas ocurran, pues está dotado de una fuerte sensibilidad para los negocios, tino financiero y capacidad para identificar las oportunidades que otros mortales no perciben. "Con todo ese potencial, transforma las ideas en realidad, para beneficio propio y para beneficio de la organización o de la comunidad". (Chiavenato y Sapiro, 2011, p. 253)

Por otra parte, y complementando los planteamientos anteriores, resulta difícil desligar el concepto "espíritu emprendedor" del emprendedor. Este "espíritu" ha sido entendido desde la óptica del empresarismo como la meta que busca lograr utilidades o incrementar su tamaño en entornos inciertos y riesgosos, mediante la creación de empresas innovadoras (Hellriegel, Jackson y Slocum, 2009).

Amaru (2008) afirma que el emprendedor es una persona que tiene la capacidad de idear y realizar cosas nuevas, características que no se encuentran en todas las personas, pues muchos carecen de las mismas por diferentes circunstancias: desde la ausencia de un entorno propicio que les haya permitido desarrollar dichas cualidades, hasta actitudes y 
creencias que son producto de visiones paternalistas e, incluso, la imposibilidad de proponer alternativas viables de proyectos ante las instancias existentes para fomentar y apalancar los emprendimientos. Ante esta situación toma mayor importancia el capital relacional del emprendedor, pues el conjunto de sus relaciones sociales y de negocio contribuyen significativamente a materializar sus emprendimientos.

\section{El emprendimiento corporativo, fuente de innovación en las organizaciones}

Usualmente, el emprendimiento ha sido tratado desde la óptica del creador de empresa que se vuelve su propio jefe y que se hace responsable de su iniciativa. Sin embargo, actualmente se acepta que el emprendimiento es una actitud humana que se despliega en diferentes contextos: uno de ellos, que se da al interior de las organizaciones ya constituidas y en plena actividad empresarial, ha sido denominado "intraemprendimiento" y "emprendimiento corporativo"; dos denominaciones acogidas en ocasiones como sinónimos, pero que presentan diferencias, como se plantea a continuación.

El intraemprendimiento, de acuerdo con Pinchot (1985), es una práctica orientada a desarrollar nuevas empresas dentro de una ya existente con el fin de aprovechar las oportunidades y generar valor. Así, continúa diciendo el autor, se trata de una serie de prácticas de negocio que permiten que personas con personalidad intraemprendedora realicen innovaciones en la empresa para su beneficio y el de sus clientes, con o sin apoyo oficial. En opinión de Kuratko, Montagno y Hornsby (1990) el intraemprendimiento ayuda a renovar a los administradores y a sus negocios, propiciando innovación y mejora en el desempeño.

En tal sentido, Antoncic y Hisrich (2000), interpretando a Stevenson y Jarillo (1990), mencionan que el intraemprendimiento es un proceso en el que los colaboradores de una organización persiguen oportunidades, por lo cual se desvían de lo habitual haciendo cosas nuevas (Vesper, 1990). Cuando se estudia el tema de intraemprendimiento, se llega al concepto de "emprendimiento corporativo", el cual es definido como el "proceso a través del cual un individuo o un grupo de individuos en asociación con una organización existente, crean una nueva organización o instigan la renovación o innovación al interior de la organización" (Seshadri y Tripathy, 2006, p. 18; Sharma y Chrisman, 1999).

Siendo así,

el intraemprendimiento es un componente del emprendimiento corporativo, desarrollado en la organización, que puede tener un impacto externo, causado por el desarrollo de nuevos productos o servicios, o un impacto interno, debido a la innovación en los procesos desarrollados por la organización, lo cual la rejuvenece y renueva. (Trujillo y Guzmán, 2008, p. 41)

De esta manera, según Antoncic y Hisrich (2003), (como se citó en Corduras, Peña y Guerrero, 2011), se pueden encontrar "diversas dimensiones [sobre] cómo emprender nuevos negocios, productos o servicios innovadores, procesos innovadores, auto-renovación, toma de riesgos, proactividad y agresividad competitiva" (p. 8).

A su vez, Amo y Kolvereid (2005) presentan una distinción entre "emprendimiento corporativo" e "intraemprendimiento". Así, afirman que ambos términos están relacionados y representan "procesos incrementales de renovación en las organizaciones a través de iniciativas de innovación llevadas a cabo por los empleados" (p. 8); en consecuencia, aseguran, los términos en mención "representan ligeramente diferentes fenómenos de renovación organizacional. Para ellos, el emprendimiento corporativo está relacionado con los procesos utilizados por la organización para fomentar actividades de innovación, a través de la iniciativa de los empleados" (Trujillo y Guzmán, 2008, p. 41); esta diferencia resalta que, en el tema de intraemprendimiento, prima la iniciativa del colaborador. De esta forma, podría considerarse al emprendimiento corporativo como una intención estratégica de la organización.

Desde esta óptica, el emprendimiento corporativo es “la transformación de las organizaciones mediante la renovación, considerada una estrategia para implementar nuevas ideas" (Amo y Kolvereid, 2005, p. 9); situación que permite un alineamiento estratégico de las actuales necesidades de la compañía con su visión futura. En contraste, 
el comportamiento del intraemprendedor es autónomo, en ocasiones no valorado en primera instancia por la alta dirección, y en el cual su surgimiento no es fruto de políticas organizacionales que incentiven la creatividad de los empleados y la innovación en la empresa. (Trujillo y Guzmán, 2008, p. 42)

Aclarada la cuestión “¿qué es el emprendimiento?", es ahora importante centrarse en la pregunta “ ¿cómo se logra?", puesto que es importante el quehacer estratégico y operacional de las organizaciones.

En esta vía, Garzón (como se citó en Montiel, González y Cervantes, 2014), plantea que:

El modelo teórico del intraemprendedor intenta predecir la incidencia de las variables independientes características organizacionales, características individuales y creación del contexto organizacional intraemprendedor sobre la variable dependiente innovación en las organizaciones. En el marco de la gestión del conocimiento, se concibe al modelo intraemprendedor para la variable características organizacionales, como el que permite sintonizar a la organización, en tanto que facilitando esta es más fácil impulsar la innovación intraemprendedora. La segunda variable, características individuales, está orientada a generar actitudes en los intraemprendedores, la tercera variable busca utilizar los conocimientos para formar y conformar equipos e identificar oportunidades, y la cuarta variable que además es la dependiente, aborda la innovación radical, gradual, arquitectural y conceptual para compartir el conocimiento tácito, explícito y virtual (p. 1690).

Garzón (2008) presenta los ítems que hacen parte de cada una de las variables anteriormente mencionadas:

1. Características organizacionales: altos intraemprendedores, los recursos y las capacidades, gestión del conocimiento y aprendizaje organizacional, y cultura organizacional intraemprendedora; 2. Características individuales: espíritu empresarial y prioridad por el proyecto interno, visión e imaginación creativa e innovadora, necesidad de actuar y alta necesidad de logro, dedicación constancia persistencia tenacidad y deseo de autonomía, destreza para organizar y trabajar en equipos autodirigidos, y líder creador de comunidad; 3. Creación del contexto organizacional intraemprendedor: formación para la innovación, conformación de equipos intraemprendedores, identificación de oportunidades, y condiciones intraemprendedoras; 4. Innovación: radical, incremental o gradual, arquitectural, conceptual, y clima para la innovación (p. 5).

En este sentido, la organización debe sintonizar las características organizacionales con su diseño estratégico y las prácticas operacionales del día a día; además, debe generar las características individuales en su talento humano para que, a su vez, se alineen con las características organizacionales. Como parte del modelo, la empresa debe utilizar de manera efectiva el contexto organizacional intraemprendedor, en el cual los dos ítems anteriores se construyen de tal forma que, finalmente, se impactará la innovación y sus resultados, todo lo cual debe compartirse con el fin de fortalecer el modelo.

Debe formularse, entonces, la estrategia corporativa dirigida hacia el emprendimiento corporativo, sobre la base de una visión emprendedora que indique de manera clara qué desea alcanzar la organización, lo cual deberá verse traducido en la definición de las tareas clave que permitan lograr los objetivos organizacionales e individuales mediante el ejercicio de comportamientos innovadores. Para este ejercicio es conveniente la creación de equipos de trabajo que agreguen valor a las actividades emprendedoras que realizan los colaboradores de la organización, lo cual debe unirse al desarrollo de las condiciones que aseguren la generación de una cultura organizacional que privilegie el intraemprendimiento.

Por tanto, es importante la propuesta, generación y mantenimiento de un conjunto de valores y creencias que acompañen la actitud de los individuos dentro de la firma (Antoncic y Hisdch, 2000) y que generen una relación positiva entre el intraemprendimiento y dichos valores organizacionales centrados en los individuos.

Para que la cultura intraemprendedora produzca los frutos esperados es necesario acompañarla de un sistema efectivo de compensación e incentivos (Kuratko, Ireland y Hornsby, 2001), basado en 
los resultados o relacionado con el desempeño de sus equipos; sistema que, en opinión de Hornsby, Kuratko, y Zahra (2002) debe ser claro y detallar los objetivos, los sistemas de retroalimentación, la responsabilidad individual y los resultados obtenidos. Finalmente, para el emprendimiento corporativo, en el emprendimiento tradicional, es importante la creación y el fortalecimiento de un ecosistema intraemprendedor que permita la interacción entre los actores, los roles y el entorno organizacional desde un enfoque sistémico que propicie un desarrollo eficaz de oportunidades, motivación individual e innovación.

Es importante presentar algunos resultados empíricos, como el de Khakbaz, Kazemi y Zarei (2011), quienes encontraron que la disponibilidad de recursos, el sistema de recompensas, la cultura corporativa, las estrategias empresariales y la toma de riesgos, son los factores de efectividad que debe ofrecer la empresa para potenciar el emprendimiento corporativo.

En adición a lo anterior, un estudio realizado en 273 empresas de la industria cerámica de Turquía "sobre la relación entre emprendimiento corporativo, formalización y centralización, concluyó que estos dos aspectos tienen impacto en los comportamientos empresariales dentro de las compañías" (Rubio, 2015, p. 104); encontrando, entonces, que el emprendimiento corporativo "es una de las estrategias clave de las organizaciones de hoy buscando adquirir o sostener la ventaja competitiva en los mercados globales" (Demirci, 2013, p. 115).

Otros autores, por su parte,

en una investigación empírica en 150 empresas de la industria manufacturera que cotizan en la bolsa de Estambul, determinaron que las dimensiones originales del emprendimiento corporativo como la innovación, la toma de riesgos y la proactividad, tienen una relación e interacción positiva con el desempeño financiero de las empresas. (Rubio, 2015, p. 104)

De igual forma, Adonisi y Wyk (2012), en su investigación realizada en Sudáfrica, hallaron que existe una relación significativa con distinta orientación al mercado, flexibilidad y factores de satisfacción del trabajo.

En resumen, el emprendimiento corporativo "es el proceso mediante el cual un individuo 0 un grupo de individuos en asociación con una organización existente, crean una nueva organización o promueven la renovación o innovación al interior de la organización" (Seshadri y Tripathy, 2006, p. 18). El intraemprendimiento tiene que ver con el desarrollo sistémico de cuatro ítems: las características organizacionales, las características individuales, el contexto intraemprendedor organizacional y la innovación.

Para su desarrollo es necesario que se encuentre atado al diseño estratégico de la organización, es decir, a su estrategia y a la formulación de una visión emprendedora que rete las capacidades organizacionales e individuales. Lo anterior debe enmarcarse en una cultura intraemprendedora, con valores y creencias orientadas al emprendimiento corporativo, reforzado por un sistema de compensación e incentivos que propicien resultados innovadores.

\section{El ecosistema emprendedor, entorno para emprender}

Para iniciar este tópico, es importante definir el concepto de "sistema", con respecto al cual Ackoff, Simon y Ashby (como se citó en Kantis, 2004) plantean que

los sistemas están compuestos de partes que interactúan, cuentan con entradas (inputs) y salidas (outputs) y sus límites son arbitrarios, variando según el foco de interés. A partir de un cierto punto, los componentes y su estructura comienzan a ser considerados como una caja negra en la cual se conocen las transformaciones de las entradas en salidas, pero no su estructura interna (p. 25).

En adición, un sistema está orientado a un propósito específico que funciona de acuerdo con las consideraciones anteriores. Por su parte, Ojeda y Rodríguez (2011) afirman que "la palabra ecosistema, de acuerdo con la Real Academia Española (RAE), significa comunidad de seres vivos cuyos procesos vitales se relacionan entre sí y se desarrollan en función de los factores físicos de un mismo ambiente" (p. 40). 
Con base en lo anterior, y a partir de la conceptualización sobre emprendimiento, se puede inferir que

existen factores de indole personal 0 individual y factores relacionados con el contexto, que entendidos bajo un enfoque sistémico, conforman el ecosistema emprendedor. Ambos factores son indispensables para que el emprendimiento se desarrolle de manera eficaz, tanto la motivación en el individuo como la existencia de oportunidades y de un contexto favorable para su aprovechamiento y aplicación en beneficio personal y colectivo. (Uribe y Reinoso, 2013, p. 15)

Arraut (2011) define al "ecosistema de emprendimiento" como el conjunto de relaciones complejas que se dan entre las instituciones y los emprendedores, en los niveles académico, social, político y económico. En este sentido, Kantis (2004) plantea el concepto de "sistema de desarrollo emprendedor" como "un conjunto de factores que, desde una perspectiva sistémica, influyen en el proceso emprendedor" (p. 25). Tales factores son sintetizados por él en siete categorías, a saber: condiciones sociales y económicas, cultura y sistema educativo, estructura y dinámica productiva, aspectos personales, redes del emprendedor, mercado de factores y regulaciones y políticas.

De forma complementaria, Isenberg (como se citó en 0jeda y Rodr, 2011), plantea que

un ecosistema emprendedor está compuesto por cientos de elementos que, según su papel 0 función, pueden clasificarse en seis categorías generales: promover la cultura empresarial, impulsar y desarrollar políticas para la promoción y desarrollo de nuevas empresas, proveer financiamiento apropiado, contribuir con servicios profesionales e infraestructura al nacimiento y el desarrollo del emprendedor, formar capital humano y hacerlo apto para iniciar y desarrollar empresas, y probar y adquirir los servicios. (p. 40-41)

En sus términos, Voelker (2012) afirma que existe una interrelación clara entre los ecosistemas emprendedores y la cultura, y que su existencia particular -al igual que las políticas y el capital humano- hacen que dichos ecosistemas difieran de unas regiones a otras. Continúa planteando que la cultura, en el ecosistema emprendedor, se interrelaciona con la creación de conocimiento y la innovación, lo que significa que interactúa con el espíritu emprendedor. Finalmente, concluye que la cultura puede mostrar la dirección apropiada de la movilidad del ecosistema emprendedor.

De otro lado, Spilling (como se citó en García, 2010), define un ecosistema emprendedor "como la interacción de los actores, sus roles y el entorno, ya que determinan el desempeño y los resultados empresariales de una región" (p. 9). Dicho sistema está conformado por las empresas que, de acuerdo con su actividad, son capaces de convocar recursos para la creación de nuevos emprendimientos. De nuevo García (2010), refiriéndose específicamente a las empresas de base tecnológica, plantea que estas se convierten en un polo de atracción de nuevas empresas y recursos territoriales que pueden beneficiarse de su implantación cercana.

Una de las ventajas del ecosistema es que ayuda a co-crear valor, como en el caso de los clusters (Pitelis, 2012), mediante la acción de los emprendedores en una región específica, que se vuelve interesante para otros emprendedores que desarrollan actividades similares. García (2010), como resultado de su investigación, concluye con respecto a los recursos que

estos son principalmente de naturaleza intangible, tales como el nivel educativo de la población (recursos humanos), el capital social (recursos sociales) y las patentes (recurso tecnológico), en orden de importancia; a ellos siguen los recursos financieros, de carácter tangible. Los recursos físicos, por su parte, no se identifican en esta investigación como críticos. (p. 18)

Por su parte, Wyld, Tölö, Heiniluoma y Ovaska (2009), en el análisis del ecosistema emprendedor de alta tecnología de Finlandia, dejan entrever que el sistema se basa en la interacción de diferentes actores, entre los que se encuentran los emprendedores, los grandes empresarios, los inversionistas y los proveedores de servicio, por una parte; y los capitalistas de riesgo, los ángeles inversionistas, las entidades financieras, los gobiernos, las escuelas, 
las incubadoras y las redes, por otra parte. Cada uno de dichos actores tiene funciones específicas en el ecosistema.

En consideración a los anteriores conceptos, se interpreta que existe una gran variedad y cantidad de elementos que hacen parte de un ecosistema emprendedor, desde diferentes enfoques, propuestas e intereses. Por lo anterior, se ha elaborado una propuesta que recoge de una manera sistémica dichos elementos (Figura 4), que se explicarán a continuación.

Figura 4.

\section{Componentes de un ecosistema emprendedor}

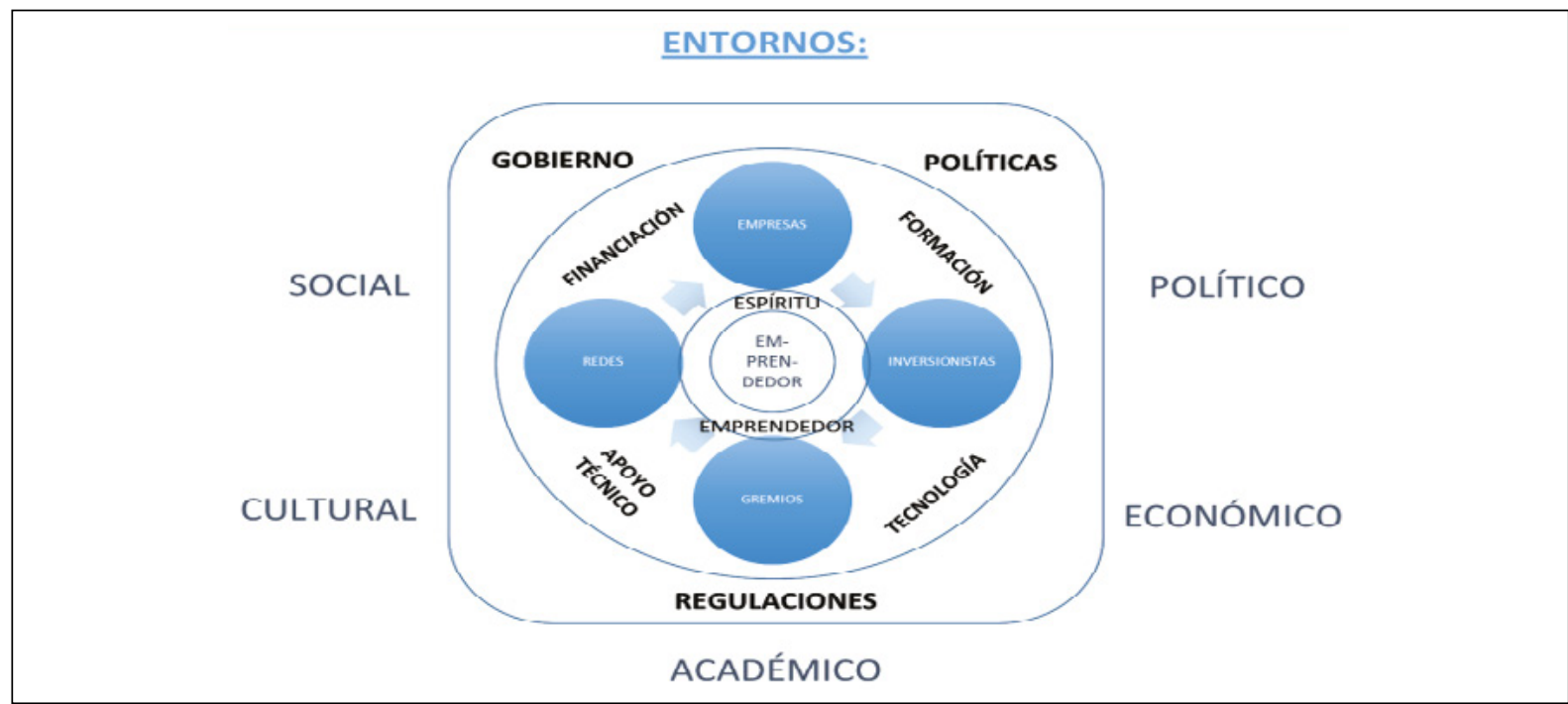

Fuente: elaboración propia.

En primera instancia, es necesario reconocer que para que se genere un ecosistema emprendedor debe existir un emprendedor; por tal motivo, este aparece en el centro del esquema, rodeado del espíritu emprendedor que debe ser motivado, modelado y desarrollado a partir de la intervención de los diferentes actores y elementos del sistema.

Alrededor de él, se encuentran los elementos más directamente asociados a la actividad empresarial. En primera instancia, las empresas (no solo la del emprendedor) que generan una relación de ayuda de diferentes maneras: dentro de una cadena productiva, proveedor-empresa, aliado-empresa, pyme-mediana empresa, entre otras. También los inversionistas, que promueven la creación, expansión y crecimiento de la empresa del emprendedor; los gremios, que realizan una labor encaminada a mejorar las condiciones de sus empresas agremiadas, mediante su representación política ante las instancias pertinentes $y$, finalmente, las redes, que permiten apalancamientos para el acometimiento de actividades que no se podrían realizar de manera individual o que, de hacerse de esta manera, podrían resultar demasiado costosas. En este segundo círculo podrían tipificarse algunas formas de asociatividad empresarial conocidas: clusters, cadenas productivas, alianzas estratégicas, uniones temporales, entre otras.

El sector productivo se encuentra rodeado, a su vez, por los actores relacionados con la financiación, la formación, el apoyo técnico y la tecnología. En cuanto a la financiación, aparecen los capitales de riesgo, los ángeles inversionistas, los fondos para el emprendimiento y el sistema financiero. Con 
respecto a la formación, es protagonista el sistema educativo en sus diferentes niveles: primario, secundario, técnico, tecnológico y profesional, con las diferentes instituciones educativas. El apoyo técnico está representado en las instituciones del sistema de formación para el trabajo, así como en entidades de investigación, experimentación y capacitación, específicas para cada sector y actividad económica. En la tecnología se encuentran las entidades relacionadas con el fomento y financiación de la investigación, ciencia y tecnología, así como los centros y grupos de investigación que están en capacidad de generar, desarrollar y apropiar tecnología.

Rodeando los componentes mencionados, se encuentra la acción gubernamental: gobierno, políticas y regulaciones. En el primer caso, se dan todas las decisiones del sector gubernamental orientadas a crear el ambiente adecuado para el fortalecimiento del emprendimiento; en el segundo, se trata específicamente de las políticas orientadas a propiciar la actividad empresarial $y$, en el tercero, todo el sistema de normas que regulan dicha actividad. Cabe anotar que en este círculo se encuentran todas las instituciones oficiales relacionadas con los anteriores elementos.

Finalmente, y en el nivel más macro del sistema, interactúan los diferentes entornos que contribuyen a la actividad emprendedora: social, político, cultural, económico y académico. Allí, se dan las relaciones que de una forma u otra soportan todo el sistema, que promueven el conocimiento y la iniciativa en la población, que vuelven particulares las expresiones del emprendimiento en una región o un país y que, al final, contribuyen a la generación de valor para todo el ecosistema. Por último, debe recordarse el sentido del concepto "sistema": todas estas partes (llamadas "subsistemas") deben interactuar armónicamente y orientarse inteligentemente hacia un propósito común.

En suma, un sistema es un conjunto de partes que se interrelacionan para lograr un propósito que justifica su existencia. El ecosistema emprendedor es un conjunto de factores de índole personal y de factores relacionados con el entorno que propician de manera sistémica el desarrollo del emprendimiento. Está conformado por los siguientes componentes: empresas, inversionistas, gremios y redes; financiación, formación, tecnología y apoyo técnico; gobierno, políticas y regulaciones; y los entornos social, político, cultural, económico y académico.

\section{CONCLUSIÓN}

El emprendimiento es un concepto complejo, que incluye la figura del emprendedor desde una perspectiva integral y con un conjunto de competencias que se despliegan en el marco de su accionar individual 0 en el interior de una organización; constituye una práctica social que se ejecuta en un entorno conformado por diferentes instituciones, conocido como "ecosistema emprendedor".

El emprendedor es un individuo que cuenta con un conjunto de características que han sido clasificadas en cinco factores: los personales, que son propios del individuo y ejercen influencia sobre su actuar; los de vocación emprendedora, que motivan y conducen a la persona para acometer cosas nuevas; los potenciadores, que apalancan los anteriores y de esa manera fortalecen el espíritu empresarial; los generadores, que son esenciales para que se desarrolle el espíritu empresarial; y los determinantes, que constituyen la chispa que enciende el emprendimiento.

Una de las competencias fundamentales para el emprendedor es el liderazgo: este actúa sobre otras competencias como la toma de decisiones, la orientación hacia los objetivos, el ejercicio del pensamiento sistémico, la actuación proactiva, la autoconfianza, entre otras. Dichas competencias están enmarcadas en tres categorías de habilidades: técnicas, interpersonales y conceptuales. De esta forma, el liderazgo contribuye significativamente en el ejercicio emprendedor del individuo y lo ayuda a lograr la dirección adecuada mediante los esfuerzos y la energía de la gente que lo rodea.

Adicionalmente, la personalidad contribuye de manera importante al emprendimiento, pues esta determina la manera como el individuo piensa, siente y actúa en una variedad de situaciones. Para el caso del emprendedor, las escalas de personalidad que son significativas son: comunicativo, expresivo, desenvuelto, agradable, cooperativo, cortés, cuidadoso, cumplido, estudioso, responsable, organizado, 
tranquilo, sereno, estable, imaginativo, creativo, accesible, conocedor y analítico.

Como complemento a las anteriores características preponderantes, se encuentra el capital relacional: en esencia, se refiere a las relaciones entre las personas y al conocimiento que se construye a partir de dichas relaciones. Estas pueden ser de negocios y sociales, dependiendo del tipo de agente con el cual se construyan, pero todas, en conjunto, contribuyen decididamente a convertir las ideas innovadoras del emprendedor en realidades y en productos innovadores.

Como actitud humana, el emprendimiento se despliega en diferentes contextos: uno de ellos, que es de gran importancia, es en el interior de las organizaciones. Emergen, entonces, los conceptos de "emprendimiento corporativo" e "intraemprendimiento". El primero, es una intencionalidad estratégica de la organización, orientada a fomentar las actividades de innovación de su talento humano, con el fin de renovar la organización; el segundo, es desarrollado a partir de la iniciativa de los colaboradores, por lo cual es un ejercicio autónomo que puede 0 no ser reconocido y estar incluido en los objetivos estratégicos de la compañía.

Desde un enfoque sistémico, es necesario tener en cuenta la existencia de una serie de relaciones entre actores, roles y entorno que propician o no el desempeño y los resultados empresariales que se obtengan en una región determinada. El ecosistema emprendedor pone en contacto al emprendedor con empresas, inversionistas, gremios y redes, así como con instituciones que se dedican a la financiación, formación, tecnología y apoyo técnico en el marco de la acción gubernamental, la regulación y las políticas. Dicho ecosistema está constituido por diferentes tipos de entornos, a saber: político, económico, académico, cultural y social.

Cuando se trata de generar emprendimientos, 0 de conducir a un emprendedor en el proceso mediante acciones educativas y de asesoría, es necesario considerar la existencia de un conjunto de elementos, unos propios del emprendedor y otros del entorno, que deben ser gestionados para asegurar el éxito en el propósito. Algunos de ellos se han analizado en este artículo: sus características personales, el liderazgo, la personalidad, su capital relación, por una parte; el emprendimiento corporativo y el ecosistema emprendedor, por otra parte.

En el presente ejercicio de revisión se han generado inquietudes con respecto a temas que deberían ser investigados, con base teórica y de manera empírica, para fortalecer el estado del arte del tema de emprendimiento. Uno de ellas podría ser la relación empírica que existe entre el ejercicio del liderazgo y el éxito de los emprendimientos llevados a cabo en regiones específicas, que incluya los tipos de liderazgo y los elementos propios del liderazgo en dicha relación. Por otra parte, una segunda propuesta tiene que ver con los rasgos de personalidad y la influencia, positiva o negativa, que cada uno de estos ejerce en el quehacer del emprendedor, de tal forma que se puedan definir, desde la práctica, los tipos de personalidad más propicios para el emprendimiento.

Investigaciones que midan el efecto del capital relacional en los nuevos emprendimientos que se hayan llevado a cabo a nivel individual (para la creación de nuevas empresas) y en los que se hayan desarrollado en el seno de pequeñas y medianas empresas de una región definida, son también recomendadas. Sin perjuicio de hacer lo propio, en cuanto al aporte del intraemprendimiento a la renovación de organizaciones y la puesta en marcha de nuevas ideas, que se podría llevar a cabo en diferentes tipos de empresa según su tamaño: grande, mediana, y pequeña. Finalmente, y con el fin de contribuir a la formulación de una política pública, es recomendable desarrollar procesos de investigación centrados en el tema del ecosistema emprendedor, sus agentes, sus roles y sus aportes al desarrollo empresarial de las regiones.

\section{REFERENCIAS BIBLIOGRÁFICAS}

Acuña, L., Araque, J., Rubio, G. y Uribe, M. (2015). ¿Por qué desaparecen las empresas?: un estudio empírico. -El caso del Tolima-. Ibagué: Universidad del Tolima.

Abdul, N. (19 de agosto de 2010). Capital relacional: el poder de las relaciones. Recuperado de: www. portafolio.co. 
Adair, J. (1990). Líderes, no Jefes. Guíe y oriente su equipo hacia el éxito. Bogotá: Legis.Adonisi,

Adonisi, M. y Wyk, R.V. (2012). The influence of market orientation, flexibility and jop satisfaction on corporate entrepreneurship. Recuperado de http://web.ebscohost.com/ehost/ pdfviewer/pdfviewer?vid=4\&sid=3161a3b3-22a845b1-867b-62ff80812370\%40sessionmgr115\&h $\mathrm{id}=117$

Amaru, A. (2008). Administración para emprendedores: fundamentos para la creación y gestión de nuevos negocios. México: Pearson-Prentice Hall.

Amo, B. y Kolvereid, L. (2005). Organizational strategy, individual personality and innovation behavior. Journal of Enterprising Culture, 13(1), 7-19.

Andrés, M., Castañeiras, C. y Richaud, M. (2014). Relaciones entre la personalidad y el bienestar emocional de los niños. El rol de la regulación emocional. Cuadernos de Neuropsicologia, 8 (2), 217-241.

Antoncic, B. y Hisrich, R. (2000). Intrapreneurship modeling in transition economies: a comparison of Slovenia and the United States. Journal of Developmental Entrepreneurship, 5(1), 21-40.

Argandoña, A. (2010). ¿Qué quiere decir gestión de Stakeholders? Pamplona: IESE.

Arraut, L. (7 de julio de 2011). Ecosistemas de emprendimiento. Recuperado de www.eluniversal.com.co

Blanco, E. (2007). Al planificar, la personalidad cuenta. Debates IESA, 12(3), 44-51.

Borjas, L. (2003). Espíritu empresarial, creatividad empresarial. Un nuevo reto. Anales de la Universidad Metropolitana, 3(2), 133-156.

Capello, R. y Fagian, A. (2005). Collective learning and relational capital in local innovation processes. Regional studies, 39(1), 75-87.

Castellanos, J. Castellanos, C. (2010). Procedimiento general para la gestión del capital relacional en las organizaciones. Contribuciones a la economía. julio de 2010. Recuperado de http://www.eumed.net/ ce $/ 2010 \mathrm{~b} / \mathrm{cccm}$.htm

Centro de Empresas y Negocios Santiago Innova - Municipalidad de Santiago. (2015). Programa emprendedores. Recuperado de: http://www.innova.cl

Chiavenato, I. y Sapiro, A. (2011). Planeación estratégica: fundamentos y aplicaciones. México: Mc Graw Hill.

Conferencia de Consejos Sociales. (2015). Glosario de competencias. Recuperado de http:// csintranet.org/competenciaslaborales/index.php?view=article $\& i d=114 \%$
3 Aglosario-g-p\&format=pdf\&option=com content\&Itemid $=138$

Contreras, F., Espinosa, J. y Esguerra, G. (2009). Personalidad y afrontamiento en estudiantes universitarios. Universitas Psychologica, 8(2), 311-322.

Corduras, A., Peña, I. y Guerrero, M. (2011). Emprendimiento corporativo en España. Madrid: GEM España - Fundación Xavier de Salas para la Dirección.

Cujiño, M. y Uribe, M. (2014). La estrategia en la historia empresarial: análisis de dos casos empresariales. Ibagué: Universidad del Tolima.

Delgado, M., Martín, G., Navas, J. y Cruz, J. (2011). Capital social, capital relacional e innovación tecnológica. Una aplicación al sector manufacturero español de alta y media-alta tecnología. Cuadernos de economía y dirección de la empresa CEDE, 14(04), 207-221. doi: 10.1016/j.cede.

Demirci, A. (2013). In pursuit of corporate entrepreneurship: How employees perceive or role of formalization and centralization. Recuperado de http://web.ebscohost.com/ehost/pdfviewer/ pdfviewer?vid=3\&sid=3161a3b3-22a8-45b1$867 \mathrm{~b}-62 \mathrm{ff} 80812370 \% 40$ sessionmgr115\&h id $=117$

Ferrández, R. y Sánchez, L. (2014). Competencias docentes en secundaria. Análisis de perfiles de profesorado. RELIEVE, 20(1), 1 - 20. doi: 10.7203/ relieve.20.1.3786

García, A. (2010). Ecosistema emprendedor para las empresas de base tecnológica: visión basada en los recursos. Tec Empresarial, 4(1), 8-21.

García, J., Álvarez, P. y Reyna, R. (2007). Características del emprendedor de éxito en la creación de pymes españolas. Estudios de economía aplicada, 25(3), 1-26.

Garzón, M. (2008). Propuesta de modelo de emprendimiento corporativo o intraemprendimiento para la innovación. Sinnc0 2008. Recuperado de www. concytec.gob.mx

Gómez, R. (2008). El liderazgo empresarial para la innovación tecnológica en las micro, pequeñas y medianas empresas. Pensamiento y gestión, 24, 157 - 194.

González, D. y Rodenes, M. (2008). La influencia del capital relacional, innovación tecnológica y orientación al mercado sobre los resultados empresariales en empresas de alta tecnología. Un modelo conceptual. Pensamiento y gestión, 25, 113-138.

Hellriegel, D., Jackson, S. y Slocum, J. (2009). Administración: un enfoque basado en competencias. México: Cengage Learning. 
Hornsby, J., Kuratko, D. y Zahra, S. (2002). Middle managers perception of the internal environment for corporate entrepreneurship: Assessing a measurement scale. Journal of Business Venturing, 17 (3), 253-273.

Jiménez, J., Lozano, M. y Varela, R. (1995). Crear empresas: misión de todos. Cali: Universidad ICESI.

Kantis, H. (2004). Desarrollo emprendedor. América Latina y la experiencia internacional. New York: BID.

Karacaoglu, K., Bayrakdaroglu, A. y San, F. (2013). The impact corporate entrepreneurship on firm's financial performance: evidence from Istanbul stock exchange firms. Recuperado de http:// web.ebscohost.com/ehost/pdfviewer/ pdfviewer?vid=3\&sid=3161a3b3-22a8-45b1867 b- 62 ff $80812370 \% 40$ sessionmgr115\&h id $=117$

Khakbaz, P., Kazemi, R. y Zarei, B. (2011). Identifying effective organizational factor son corporate entrepreneurship in Tehran municipality's department of urban services. Recuperado de: http://web.ebscohost.com/ehost/pdfviewer/ pdfviewer?vid=4\&sid=3161a3b3-22a8-45b1867 b-62ff80812370\%40sessionmgr115\&h id $=117$

Kuratko, D., Montagno, R. y Hornsby, J. (1990). Developing an intrapreneurial assessment instrument for an effective corporate entrepreneurial environment. Strategic Management Journal, 11 (edición especial), 49-58.

Kuratko, D., Ireland, R. y Hornsby, J. (2001). Improving firm performance through entrepreneurial actions: Acordia's corporate entrepreneurship strategy. Academy of Management Executive, 15(4), 60-71.

Maestres, R. (2009). Lecciones de Winston Churchill CEO. Debates IESA, XIV(3), 8 - 10.

Minniti, M. y Bygrave, W. (1999). The microfoundations of entrepreneurship. Entrepreneurship Theory and Practice, 23, 41-52.

Mintzberg, H. (1980). The nature of managerial work. $\mathrm{NJ}$ : Prentice Hall.

Montiel, 0., González, A. y Cervantes, D. (2014). Psicología del intraemprendimiento: una aproximación desde un estudio de caso en la industria maquiladora de Cd. Juárez, México. Conference on Business and Finance Proceedings, 9(1), 1689 - 1699. Recuperado de http://www.theibfr.com/ARCHIVE/ ISSN-1941-9589-V9-N1-2014.pdf

0jeda, E. y Rodríguez, A. (2011). El ecosistema nacional de emprendimiento. Revista Debates IESA, (XVI), 4.
Orrego, C. (2009a). La fenomenología y el emprendimiento. Pensamiento y Gestión, 27, 235-252.

Orrego, C. (2009b). La fenomenología y el emprendimiento. Revista Ciencias Estratégicas, 17(21), 21-31.

Pérez, P., Espinoza, R., Tapia, H., Márquez, A. y Acevedo, J. (2006). El emprendedor en México: ingenio vs. innovación. I Congreso Iberoamericano de Ciencia, Tecnología, Sociedad e Innovación CTS+I. Recuperado de www.oei.es/historico/memoriasctsi/mesa12/ m12p25.pdf

Pinchot, P. (1985). Intrapreneuring: why you don't have to leave the corporation to become as entrepreneur. Scranton: Harper Collins.

Pitelis, C. (2012). Clusters, entrepreneurial ecosystem co-creation, and appropriability: a conceptual framework. Industrial and Corporate Change, 21(6), 1359-1388. doi:10.1093/icc/dts008.

Rodríguez, A. (2009). Nuevas perspectivas para entender el emprendimiento empresarial. Revista Pensamiento y gestión, 26, 94-119.

Rodríguez, M., \& Díaz, R. (1997). ¿Son universales los rasgos de la personalidad? Revista Latinoamericana de Psicología, 29- (1), 35-48.

Rubio, G. (2015). Las contribuciones del intraemprendimiento a la estrategia de manufactura. Revista Dimensión Empresarial, 13- (1), 95-109. doi: http:// dx.doi.org/10.15665/rde.v13i1.340

Santamaría, A., Moreno, E., Torres, E. y Cadrazco, W. (2013). La influencia de la familia en el emprendimiento empresarial. - El caso de tres pymes de los sectores comercial y de servicios de la ciudad de Sincelejo Sucre. Revista Pensamiento Gerencial, 1, 90-107.

Seguí, E. y Server, I. (2010). Las cooperativas de crédito y su entorno en el contexto de la crisis bancaria: análisis de su capital relacional como base desde la que explotar oportunidades. CIRIEC España. Revista de economía pública, social y cooperativa, 68, 35-59.

Seshadri, D. y Tripathy, A. (2006). Innovation through intrapreneurship: The road less travelled. Vikalpa: The Journal for Decision Makers, 31(1), 17-29.

Sharma, P., y Chrisman, J. (1999). Toward a reconciliation of the definitional issues in the field of corporate entrepreneurship. Entrepreneurship theory and practice, 23, 3-11.

Trujillo, M. y Guzmán, A. (2008). Intraemprendimiento: una revisión al constructo teórico, sus implicaciones y agenda de investigación futura. Cuadernos de Administración, 21(35), 37-63. 
Uribe, M. y Reinoso, J. (2013). Emprendimiento y empresarismo. Bogotá: Ediciones de la U.

Varela, R. (2008). Innovación empresarial. Arte y ciencia en la creación de empresas. ( $3^{\mathrm{a}}$. ed.). Bogotá: Pearson Educación de Colombia.

Vargas, J. y Campos, R. (2011). Habilidades emprendedoras en los jóvenes universitarios zacatecanos. Revista ECORFAN, 2(5). 70-90.

Vesper, K. (1990). New venture strategies. Englewood Cliffs, N.J.: Prentice-Hall.

Voelker, T. (2012). Entrepreneurial ecosystems: evolutionary paths or differentiated systems? Business Studies Journal, 4(2), 43- 61.
Wyk, R. y Adonisi, M. (2012). Antecedents of corporate entrepreneurship. Recuperado de http:// web.ebscohost.com/ehost/pdfviewer/ pdfviewer?vid=4\&sid=3161a3b3-22a8-45b1867b-62ff80812370\%40sessionmgr115\&h id $=117$

Wyld, L., Tölö, M., Heiniluoma, A. y Ovaska, K. (2009). High Tech and Growth Entrepreneurship Ecosystem. Helsinki, Finland: Amcham.

Zárate, R. y Matviuk, S. (2012). Inteligencia emocional y prácticas de liderazgo en las organizaciones colombianas. Cuadernos de administración, 28(47), $89-102$. 